\title{
LAS INCIVILIDADES DE LA SOCIEDAD CIVIL
}

\author{
Darin McNabb \\ Professor da Faculdade de Filosofia \\ da Universidad Veracruzana, México. \\ E-mail: darin@dino.coacade.uv.mx
}

\section{Resumen}

El artículo busca subrayar y calificar la sociedad civil en relación con el Estado, teniendo en cuenta las posibilidades efectivas de la democracia. Sin alejarse de una visión democrático-liberal, se defiende la idea de una ciudadanía positiva, en el sentido de la acción libre de los ciudadanos en función del bien común y, en clara oposición al Estado, con el reto de corregir sus distorsiones.

Palabras clave: incivilidad; sociedad civil; ciudadanía positiva.

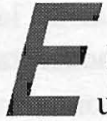

1 sociólogo o científico político de cincuenta años de edad es una cosa lamentable ver. Hace treinta años era un estudiante que se embebía del discurso liberaciónaista de la teoría marxista. Muy probablemente tenía un poster de Che Guevara, y se encontró en un tiempo que pareció al borde de un cambio social significativo. Pero con el paso de tiempo parecía que los ricos se en enriquecían más y los pobres cada vez tenían menos. Parecía que una gran oportunidad se habia perdido. Como profesor empezó a ver cómo el marxismo desaparecía más y más del debate intelectual, reemplazado por cosas como el pos-estructuralismo, la deconstrucción, y la posmodernidad. Mientras tanto, el muro de Berlin cayo, la bolsa subio, y gente como Fukuyama anunciaba el cierre hegeliano de la historia con un liberalismo globalizado como su fin triunfante. Nuestro sociólogo se encuentra ahora en el salon con sus alumnos al comienzo de un nuevo milenio y lee de Das Kapital como si él fuera una fantasma efectuando los bellos pero secos ritos de una mitología antecuada. 
Aunque se podría discutir mucho sobre la crisis del marxismo hoy en día, me parece que la tarea urgente de la teoría política al cierre del siglo $\mathrm{XX}$ es encontrar algun punto intermedio entre un estado totalitario y paternalista, y un mercado privado, anárquico, y radicalmente auto-absorto. Entre los varios intentos que ha habido para encontrar este punto, él que me interesa aquí es la teoría generalmente identificada como la sociedad civil.

Debo admitir que me consta esde hace poco tiempo que pueda entenderse la sociedad civil como una postura política contemporanea. La primera imagen que se me occurió al escucharlo menciónado en una discusión política fue la de señoras inglesas bien vestidas tomando té y hablando de opera. Pensaba en poderes coloniales imponiendo el decoro del orden cultural y la gala social en cosas tales como las desordenadas rebeliones de la gente indigena y las expresiones idealistas y licenciosas de los jovenes. Pensaba en profesores conservadores con un sueldo de tiempo completo y un nuevo Jetta reacciónando con una cansada indignación a la política extrema y el nihilismo posmoderno. En fin, imaginé que los proponentes de esta teoría llamaba a un regreso al orden civil del Porfiriato.

Pero parece que estaba equivocado. La noción actual de la sociedad civil tiene un largo y distinguido linaje, cuya raiz se encuentra en los teóricos del contrato social, Locke y Rousseau, así como en Montesquieu y Thomás Jefferson. En aquel entonces atacaban a las monarquías. Ahora son las corporaciones multinaciónales y los gobiernos burocráticos. El hilo común que corre por la historia de este pensamiento hasta hoy en día es el énfasis puesto en el papel de los ciudadanos en la vida política de la sociedad. Que en lugar de que la fría economía o la ideología política determine la naturaleza del espacio social, los ciudadanos deben crear y nutrirlo activamente.

Aunque la sociedad civil no tiene ningún manifiesto que proclama su doctrina, parece que nació en los movimientos populares contra el comunismo, los que resultaron, por ejemplo, en el "perestroika" de Gorbachev y en la revolución checa iniciada por Vaclev Havel. En su sentido más general la sociedad civil se refiere, como he menciónado, a la acción de ciudadanos en la creación y gobernación de su vida cotidiana. En el sentido más desarrollado de los teóricos contemporáneos, 
la sociedad civil es aquel espacio ocupado por ciudadanos cuando no estan en cuestiones del gobierno (votando, siendo jurado, pagando impuestos), ni del comercio (trabajando, produciendo, comprando, consumiendo). Tal actividad cotidiana incluye ir a la iglesia, realizar un servicio social, participar en una asociación cívica, contribuir a una institución benéfica, o asumir responsibilidad en una organización cultural en la comunidad. Entonces, las organizaciones que definen la actividad de la sociedad civil se involucran no en el gobierno ni el comercio sino en la cultura, la educación, la información, el desarrollo, el medio ambiente, los derechos humanos, etc. En fin, podriamos definir la sociedad civil como aquel espacio en la esfera publica donde grupos, movimientos, y individuos auto-organizados y relativamente autónomos respecto al gobierno, intentan articular valores, crear asociaciones y solidaridad, y promover sus intereses.

Entonces, ¿que hay de mal en todo esto? Parece maravilloso. Pues, quisiera acercarme a una respuesta vía dos enfoques: uno puramente analítico, inspirado por el trabajo de Foley y Edwards; y uno genealógico, sugerido por el estilo filosófico de Foucault.

Para empezar, hay algunas ambigüedades sobre la definición. En varias aplicaciones de la noción de sociedad civil los negocios, o en general "el mercado", quedan fuera de la acción de la sociedad civil, pero como preguntan Edwards y Foley, ¿implica entonces la exclusion de toda asociación economica? ¿Estan ajenos los grupos comerciales, las organizaciones profesionales, y los sindicatos? Y donde ubicamos las organizaciones políticas? ¿Debemos distinguir entre la sociedad política y la de lo civil? Si es asi entonces “ . . ¿como se distinguiria entre las asociaciones políticas como tal y las actividades de grupos en la sociedad civil? ... ¿Cuando se convierte lo civil en lo político?"

Pero aún más problematico son cuestiones sobre la viabilidad de la obtención de los fines de tal sociedad. Pues cuales son estos fines? Los teóricos de la sociedad civil no lo especifican. Hablan vagamente de justicia, libertad, y auto-determinación, pero como cualquier revisión de la historia de la filosofía política mostrará, este fin ha variado de época a época. Platón lo llama "el bien" pero habla de él en metáforas. No se nos puede mostrar con sencilla claridad porque, según él, es imposible. Aristóteles, habiendo aprendido de su maestro y intentando evitar las 
dificultades de su posición decía que el bien es específico a cada sociedad. El punto de interés para nosotros es cómo los diversos elementos de la sociedad civil pueden reformar los abusos de gobiernos burocráticos y fríos multinaciónales si posibilemente cada uno (un grupo religioso, una alianza profesional, y una asociación educativa, por ejemplo) tiene una visión distinta del bien? Qué es lo que previene que la sociedad civil se despedaze en facciones atrincherados o que se degenere en distintos grupos de intereses especiales? Esto es una posibilidad vislumbrada en el celébre análisis de Alexis de Tocqueville en su libro Democracy in America. Aunque identificaba la asociación civil como la fuerza del joven país, tenía miedo de que podría rebasar sus limites y caer en la desintegración. Tal miedo fue confirmado con el comienzo de la Guerra Civil en 1861. Aquí la acción de la sociedad civil condujo al opuesto de sus supuestos fines. Foley y Edwards advierten que "Movimientos sociales pueden representar una visión armada y paranoica de la responsibilidad (por ejemplo, el movimiento milicia en los Estados Unidos) o un rechazo de la responsibilidad social más alla del grupo inmediato (como en el caso de ciertos movimientos religiosos).

Este peligro es precisamente lo que previó Thomás Hobbes hace más que 400 años. En el Leviathan define el bien en términos negativos, como el opuesto de lo que para él era el mayor mal - la guerra civil. El bien, entonces, es lo que evita la guerra, y según la argumentación de Hobbes tiene que ser un contrato social que concentra el poder en un solo hombre. ¿Por que? Parece tan extraño que el primer teórico del contrato social, precursor de la teoría de la sociedad civil, concluye lo que plenamente contradice los fines de la sociedad civil contemporánea. Pues, Hobbes reconoció que un contrato (o convenio más bien) entre ciudadanos, sin la espada, es inútil. Racionalmente, cada quien sabe que debe cumplir el convenio, pero la realidad es que sus pasiones le ganan, y si no teme una fuerza mayor que exige el cumplimiento, es muy probable que no cumplirá. El "pegamento" que une la sociedad no es la razón o la buena voluntad, sino la fuerza. Es un fenómeno que vemos realizado en los anteriores satelites de la Union Sovietica. Con la desaparición de la espada, las feas emociones étnicas y avaricias mandan, y no la razón. Esto explica el resurgimiento de la ideología nazi entre los "skinheads" en Alemania y del partido comunista en Rusia. 
Parece que la gente, por lo menos algunos, quieren regresar al puño de hierro. Pues los teóricos de la sociedad civil dirían que después de tanto tiempo bajo un control hegemónico la gente necesitan tiempo para poder controlar las salvajes emociones y organizarse para lograr la auto-gobernación. Para hacer un omelette hay que romper huevos. Parece desordenado ahora pero con tiempo tendremos un omelette con todos los huevos unidos. Pues esto es lo que me conduce al otro metodo de analisis sugerido por Foucault. Para lograr el omeltte hay que batir los huevos para que se unan. La pregunta es, ¿qué es lo que bate los huevos, y qué implicaciones tiene esto para los fines de la sociedad civil?

Bueno, dejenme empezar por decir que lo que los proponentes de la sociedad civil describen es, en general, una visión más interesante, vital, y dinámica que la monotonía sofocante de la burocracia gurbermental o el consumismo homogeniezado del liberalismo capitalista. Estoy a favor de la diversidad y la acción independiente. Pero debemos tomar cuidado en no confundir entre los dos sentidos de la palabra 'civil' como usada en 'sociedad civil.' En ingles existen las palabras 'civil' y 'civilian.' Esta quiere decir un ciudadano ordinario que ni pertenece al ejército ni esta involucrado en el gobierno. Aquella, aunque connota la esfera de acción del ciudadano, se usa más para significar orden, obediencia, y decoro. Es respecto a este ultimo sentido que debemos tener cuidado cuando hablamos de la sociedad civil. Ciertamente, la visión de la sociedad civil es una que está compuesta por ciudadanos que trabajan juntos para crear y resolver los problemás del mundo en que viven. Pero que debemos asumir que esta actividad es la respuesta a los males sociales, una que creará orden, justicia, y una democracia plena, es algo que debemos hacer cautelosamente. ¿Por qué?

Primero, a mi me parece que la sociedad civil no es una teoría en el sentido fuerte del término, es decir, algo que conceptualiza la realidad de la esfera política en términos estructurales, así como hace Hobbes con la psicología humana o Marx con las fuerzas productivas. La sociedad civil queda atrincherado dentro del paradigma liberal, operando no como una teoría que explica la realidad política y social mejor que el liberalismo, sino más bien como una especie de "curita" ad-hoc. Parece tratar el síntoma en lugar de la causa de nuestros males. Una interpretación aun más radical sería que la noción de la 
sociedad civil, sin darse cuenta, es un cómplice en el ardid ideológico del capitalismo liberal. Digo esto pensando en una de las lemás más eficaces de la administración de Bush en los EE.UU. - "mil puntos de luz." Con esto hace referencia precisamente a las organizaciones locales que no espera a que el gobierno actue en la resolución de los problemás sociales. Aunque suena bonito, lo que quería decir Bush, así como Reagan, fue que la salud y la educación no son tan importantes como las subveciones gubernamentales para corporaciones ricas. La sociedad civil no es algo que reemplazará formas actuales de liberalismo político y economico. Más bien parece ser concebida como una manera de suavizar los males efectos de estos.

El punto de partida para la sociedad civil es el hecho de que el mundo político hoy en día esta lleno de injusticia, corrupción, y el abuso de poder. Hay una elite con acceso al poder debido al cual se benefician, y una mayoría que sufren por ser sojuzgados a un sistema impersonalizado que parece más alla de su control. La única manera de cambiar esta situación es lograr una democracia más completa y real. Hay que dar el poder a la gente, o como dice Labastida, "que el poder sirva a la gente." Entonces el argumento es que se puede realizar esto solamente donde los ciudadanos estan directamente activos en las decisiones políticas que les afecte cotidianamente. Pero ¿que forma toma este poder en la visión de la sociedad civil? Veo dos maneras de responder a esto.

1) Primero, en general me parece que el tipo de poder democratico que estos grupos locales ejercen es superficial y cosmético. Hace un momento dije que la gente esta harta de la corrupción y que se siente enajenado del espacio vital en que viven. Pertenecer a una organización social local les hace sentir involucrado. Conocen a otra gente y sienten un sentido de solidaridad. Y aunque expresan su voz y logran, de vez en cuando, resultados concretos, esto esta lejos de ser una expresión de poder democrático real - así como hacer más grande el tamaño de la jaula de un animal no hace nada en cambiar el hecho de que permanece en una jaula.

Todos las actividades asociadas con la sociedad civil, sean 
las de las ONGs, los institutos independientes, las asociaciones comunales, o lo que sea, todas son constituidas por su posición relaciónal dentro de una estructura de poder. Tal y como esta ahora, la noción de sociedad civil concibe la acción democratica fuera de las esferas del gobierno y del comercio. Como tal el ideal de una plena participación democratica nunca se logrará. Será un reacciónismo ad-hoc, un narcotico que disfraza la realidad económica y geopolítica que constreñe la vida social. Entonces, para lograr este ideal democrático, la meta de la sociedad civil tiene que extender esta esfera de acción civil tal que cubra y regule toda acción dentro del grupo social, incluso en las esferas políticas y económicas. Pero si desaparecieran estructuras actuales de poder, la cualidad civil asociada con la organización y acción independiente y local perdería su sentido.

2) Esto me conduce a mi segunda observación sobre la forma que el poder toma en la visión de la sociedad civil. Para empezar, quisiera citarle a Mario Magallon Anaya, filósofo y investigador en el Centro Coordinador y Difusor de Estudios Latinoamericanos de la UNAM. En su articulo, "Democracia, Sociedad Civil, lo Publico y lo Privado en America Latina" dice, "La democracia se puede definir de muchas maneras, pero na hay definición que pueda excluir de sus connotados la visibilidad o transpariencia del poder". (Anaya, p. 86.) Parecería que la meta de la sociedad civil es de diluir la concentración de poder y extenderlo igualmente entre todos los miembros del cuerpo social tal que sea simétrico y transparente. Esto es lo que nuestras constituciones dicen que tenemos por derecho. Pero que se realizara tal cosa, a mi me parece imposible. Tal sociedad sería una abstracción. Todo objeto en el mundo cultural, sea una ley, una idea, una institución, o una costumbre, es el resultado de una relación asimétrica de fuerzas sociales que lo engendra. Si, como una sociedad, lograramos extender tan ampliamente la esfera civil, cesarían los efectos de poder, trayendo consigo la democracia, la justicia, y el bienestar? No necesariamente. 
No fue por razones insignificantes por lo que Platón criticó la noción de democracia. Imagínense que todo miembro de la sociedad tuviera un control remoto y que pueda votar sobre cualquier asunto que tenga que ver con la esfera social a través de la televisión. Sin duda eso sería la plena democracia, pero ¿constituiria la libertad que la democracia quiere realizar? No. Como Magallon Anaya continua diciendo,

"Un factor fundamental en la democracia y en la sociedad civil es el de
la libertad. Para Isaiah Berlin la concepción liberal de la libertad como
libertad negativa excluye de forma expresa el tema de las condiciones
que hacen posible el ejercicio de esta. Por eso se requiere de asumir que
la libertad implica tambien las condiciones de su realización, o como
este autor la denomia, como libertad positiva, lo cual conduce a volver
a plantear radicalmente la idea liberal de democracia" (p. 89).

Según esto, una "democracia de control remoto" sería una imagen palida de la libertad que espera posibilitar. Sería negativo y no positivo. Una libertad positiva implica más. Como dice Anaya, "En la perspectiva latinoamericana estos retos nos llevan no solo a la exigencia de mayores niveles de igualdad económica, social y política, sino tambien de autonomía y autodesarrollo de los individuos... [1] idea de libertad pierde sentido si no tiene como objetivo el autodesarrollo de . . los individuos" (p. 90).

Lo que la libertad positiva implica es el autodesarrollo, un condiciónamiento o preparación del sujeto para que pueda participar como actor en el escenario social. Como mencióne al principio, la noción de la sociedad civil se remonta hasta los teóricos del contrato social. Y aunque más de doscientos años nos separan de ellos podemos ver muy claramente sentimientos similares expresados en el Contrato Social de Rousseau, cualquiera que rehuse obedecer a la voluntad general, será obligado a ello por todo el cuerpo; lo cual no significa otra cosa sino que se le obligará a ser libre, pues tal es la condición que, otorgando cada ciudadano a la patria, le garantiza de toda dependencia personal, condición que constituye el artificio y el juego del mecanismo político y que es la única que legitima las obligaciones civiles, las cuales, sin ella, serían absurdas, tiránicas y quedarían expuestas a los mayores abusos. 
Lo que tenemos ahora son precisamente "mayores abusos" y la manera de evitarlos y de realizar una plena democracia positiva, segun Rousseau y aparentamente los proponentes de la sociedad civil, es de informar la acción de los miembros de la sociedad con una cierta mitología social que hace cohesiona la voz en que hablamos. Vemos una mitología similar expuesta por Platón en la Republica. Ahí se llama la mentira noble. Pero más recientamente lo vemos en una artículo de Norbert Lechner (1966) donde dice, “ . . . la vida social no puede prescindir de mecanismos de cohesion social. Transformar la diversidad factica supone un ordenamiento: un orden articulado de las diferencias."

Pues, ¿cuales son estos mecanismos? La fuerza bruta es una manera, pero esto conduce a la falta de libertad por el cual criticamos los paises comunistas del siglo veinte. El aliciente de dinero y el mercado libre es otro, pero esto conduce al individualismo atómico y la falta de solidaridad social que infecta el modelo neoliberal. Tal vez algo como la mentira noble que mencióna Platón. Ciertamente esto realizaría la cohesion social que es necesaria en la visión de la sociedad civil. ¿Pero por eso seríamos libres? ¿Sería la sociedad una democracia? Sería una democracia en el sentido literal de ser un mando de la gente, pero no sería libre en el sentido especificado arriba. Los efectos de poder, que antes estuvieron en las manos de pocos queda ahora tan sólo desplazado hacia otra forma. Como aprendimos de la biología - a la naturaleza no le gusta un vacio. El poder que anteriormente ejercía el soberno ahora es ejercido por el cuerpo social, o lo que Rousseau llamaba la voluntad general.

La gran paradoja de la teoría democratica es que lo que lo posibilita es el ejercico de una fuerza que es contrario a la misma naturaleza de la democracia. Como dice Rousseau, "se le obligará a ser libre." El matrimonio de fuerza y libertad forma una de las antinómias aparentamente más irresolvibles del pensamiento político moderno. Hemos sido ciegos a esta antinómia porque concebimos el poder y la fuerza en términos de la libertad negativa. Pero en la modernidad, como señala Foucault, los mecanismos a través de los cuales el poder se ejerce son mucho más sutiles y, a su juicio, potentes. El autodesarrollo que mencióna Anaya no es un proyecto de nuestro libre albedrio, sino una violencia realizada por prácticas discursivas y técnicas de 
observación y examen que normalizan al individuo. No somos forzados por una arma a aceptar la ideología del estado. Nosotros mismos formamos y consolidamos la mentira noble de nuestra sociedad por las actividades aparentamente inocuas que constituyen la misma esfera de la sociedad civil.

Un analisis del pensamiento de Foucault sobre este punto llevaría unas dos o tres ponencias más. Para terminar quiero nada más señalar que la idea de la sociedad civil me parece interesante y valiosa. De hecho la política del mismo Foucault enfatiza un activismo en el nivel local que desafia a toda la gama del ejercicio de poder. Es solamente que debemos cuidarnos en ver a la noción de la sociedad civil como una gran respuesta. La democracia que espera realizar es algo que, a mi juicio, estará en un constante proceso de formación. La libertad no es algo que disfrutaremos en un lugar utópico en el futuro. Para mi eso es una abstracción. Más bien la libertad es algo que se realiza en el constante desafio de los ejercicios de poder que conforman lo que somos. Como dice Foucault (1977), "(todavía esta por añadirse la cita pero con eso termina la ponencia).”

\section{Referencias Bibliográficas}

FOLEY, Michael y EDWARDS, Bob. The Paradox of Civil Society, Journal of Democracy, v.7, n.3, 1996.

RABINOW, P. The Foucault Reader, New York: Pantheon Books, 1984.

FOUCAULT, Michel. La Historia de la Sexualidad, V. 1, México: Siglo Veintiuno Editores, 1977.

LECHNER, Norbert. ¿Por qué la política ya no es lo que fue?, Leviatán. Revista de hechos e ideas, n. 63, España: II Época, 1966.

MAGAllon ANAYA, Mario. Democracia, sociedad civil, lo público y lo privado em América Latina, Estudios Latino Americanos, Año II, n. 2-3, s/d. 


\section{Abstracts}

This article aims at emphasizing and qualifying civil society in its relationship with State, considering the effective possibilities of democracy. Without keeping away from a liberal-democratic view, the text tries to defend the idea of a positive citizenship, in the sense of the citizens' free action aiming at common welfare, and in clear opposition to the State, having in mind the correction of its distortions.

Key-words: incivility, civil society, positive citizenship.

\section{Resumo}

O artigo busca destacar e qualificar a sociedade civil em relação ao Estado tendo em conta as possibilidades efetivas da democracia. Sem afastar-se de uma visão democrático-liberal, o autor defende a idéia da cidadania positiva, no sentido da ação livre dos cidadãos em função do bem comum e em clara oposição ao Estado, com o objetivo de corrigir suas distorções.

Palavras-chave: incivilidade; sociedade civil; cidadania positiva. 